\title{
When Funds Won't Stretch: Faculty and Organizational Development Projects for Miniscule Budgets
}

Susanne W. Whitcomb

California State University-Long Beach

When available funds and the needs for faculty and organizational development do not match, the resulting stress often is accompanied by a closing-in of the range of vision so that alternative ways of meeting needs may not be perceived. A process may take place in which the cost of each desired training event or equipment or program is computed and then items are reduced or eliminated to bring about a "balanced budget." This process may be useful at the close of a problem solving process after all options and their assets and liabilities have been examined, but when inserted at the start, it often results in a truncated plan that pleases no one and perhaps is even worse than useless because of the awareness of harsh limitations that it fosters.

What is needed is a shift of consciousness and energy away from lack-lack of funds, lack of resources, lack of support, lack of personnel-to a concentration on all the possible actions that would move a program toward effective operation.

Intention-declaration-action: these unlock the door and make movement possible. In turn, the movement generates a flow of energy, bringing in the ideas and resources necessary to accomplish the goal. There is acknowledgement that problems and slowdowns will arise, but in this process a barrier or a block is not judged as a failure, but as an irritation on the road to success. Negative events and circumstances have only as much power as we give to them. 
This paper describes no and low cost faculty development and organizational development ideas which can be adapted to circumstances in a variety of institutions and departments. These ideas are clustered around six basic questions which emerged from a review of faculty responsibilities for teaching, curricular development, research and scholarly activities, and university and community service.

A. How can we provide an intellectually stimulating environment for the faculty when we can't afford to bring in big-name speakers?

1. Faculty who are being interviewed for possible hire are often invited to give presentations to department faculty and others in the school. This gives faculty on the home campus an opportunity to assess the teaching style and methods of the applicant, as well as gain some exposure to different teaching techniques.

2. An "Executive in Residence" program has been developed in some schools with the assistance of their advisory boards. An expert in a particular field from the community is scheduled during a semester to confer with faculty and students, speak to classes, speak to faculty, and sometimes teach one course.

3 . When faculty attend conferences, they are encouraged to commit themselves ahead of time to a report-back session to share what they have learned with their colleagues.

4. Some universities use an interim day between semesters to present a program of seminars by the faculty for the faculty. These address issues and topics of interest to faculty.

5. In some institutions, faculty applying for promotion give presentations on their research activities to faculty in the department, school and university community.

6. Faculty who present papers at regional or national meetings also may be invited to present the same paper to home campus colleagues.

7. When there are not enough resources to bring in specialists or consultants, one possible answer is to recruit a visiting professor for one semester or one year. This person, in addition to teaching, might provide orientation to new techniques for department faculty, train or re-train faculty in new technology, 
assist a department in setting up a new program, or assist with preparations for accreditation visits.

B. How can department faculty provide their own feedback and inservice training without a formally designated development person?

1. In some departments ad hoc committees of faculty teaching the same course have met regularly to share exercises, short cuts, and teaching strategies. They have discussed such topics as ways to cut down on the time it takes to read and score essays without loss of effective evaluation; how to encourage increased classroom discussion; what current issues relate to class content; how to encourage students to develop computer skills through class assignments. A similar plan is an informal program of brown bag lunches with conversation focused on a different issue or topic each week. In some universities, "Teaching Circles" are formed of five or six faculty, including at least one new teacher. These persons share materials, visit one another's classes, and meet to discuss teaching techniques that work.

2. In a faculty mentor program, a senior professor is usually teamed with a newly hired faculty member. This one-on-one relationship can provide information about local campus mores, how to prepare for advancement in the ranks, how to enhance classroom teaching skills, and the resources available on campus in a variety of support areas. Sometimes the mentors of new faculty present a workshop in the spring to share successful processes and practices. Sometimes mentoring aspects are made available to all faculty, with voluntary programs where faculty act as resources to other faculty by visiting classes or being visited, by giving feedback, and by giving presentations.

3. Faculty acknowledged by their peers as exceptional teachers and scholars have been videotaped in the classroom. Sometimes this tape will have voice-overs by the instructor explaining the rationale for certain activities and the main point of the session being taped. These tapes are viewed by interested faculty at brown bag discussion sessions.

4. In some institutions, research on teaching is done in cooperation with students in research courses.

5. Some faculty groups have formed Quality Circles to 
deal with issues of interest and concern. At the University of Ottowa, Quebec, Canada, faculty circles deal with teaching issues. In the process, the group identifies problems, analyzes the problems, gathers data, displays the information to the entire circle, selects one problem, selects causes, brainstorms possible solutions, and develops an action plan to present to the appropriate decision-makers. Sometimes the quality circle process can be applied in the classroom itself, to address concerns that either the students or the instructor bring up.

6. A process called Small Group Instructional Diagnosis (SGID) was developed by Joe Clark of the University of Washington. At the invitation of an instructor, a group interview of a class is conducted by a faculty member trained in the process, to provide feedback for the instructor. This has produced very positive comments both from faculty members visited and students.

7. A Faculty Advocate System is used in some institutions in which a person in each department serves as an advocate for faculty development.

8. A process in which articles and papers are circulated among a network of persons with similar interests can result in collaboration and sharing of scarce resources.

9. Some schools schedule regular seminars in which faculty share research findings with colleagues. These may be formal presentations, or informal "brown bag" meetings. A part of these sessions may include tips on funding for research.

10. Another type of seminar gives an opportunity for a faculty member to present a working paper and get feedback and ideas from colleagues before the paper is submitted for review.

11. Some schools have a person designated as "match maker" to match faculty interest and expertise with grant announcements and other faculty interested in the same area.

12. Part of the faculty mentor program often addresses the ways new faculty can get involved in service to the University through committee work or other means.

13. Some universities encourage "grass roots" groups of faculty across disciplines to hold informal seminars/colloquia around certain themes, e.g., new paradigms, active learning, values of the university, etc.

14. In some locations, an internal capital campaign has 
raised needed funds for faculty development. Faculty and staff were asked to designate donations for the faculty development program as an income tax write-off.

15. A carefully documented plan for working with part-time or adjunct faculty will save much time and energy on the part of all parties. An ounce of orientation will save a pound of tangled misunderstandings.

16. Another time and energy saver (remembering that time is money) is the creation of a department procedures notebook built with input from department, school and staff members and regularly updated. In addition to clearly spelling out procedures and practices, it could show the reference, and the name and campus phone of the person to contact if there are additional questions. A summary book with policies listed alphabetically makes a quick reference for faculty members as well as staff members.

\section{How can department funds be conserved and effectively utilized?}

1. Regular meetings, at least twice a month, of department chairs and the dean makes possible clarification of the budget process so that deadlines are not missed in which department monies revert to higher levels of administration, and so that information on cost saving measures can be quickly disseminated. These regular meetings work well if they are informal, yet focused, action oriented, solution centered, adhere to the published time schedule, and regularly follow up on action decisions. In addition, when the minutes are distributed to all faculty, it is an excellent communication tool.

2. Departments which develop procedures which assist units to carefully document use of funds and other resources and which shows the benefits and results of these expenditures often find themselves in a position to more easily request and receive additional support as opportunities arise.

3. Quality Circles have been effective in many organizations in achieving cost-effectiveness.

4. Faculty trained in accounting or other financial skills can assist schools and departments in setting up systems that work well for administrators and staff. Faculty trained in programming and other computer skills can create programs 
to monitor and balance expenditures daily or weekly. They can also train persons to use these programs and procedures.

5. Some plant operations divisions are beginning to set up systems where departments can do some services for themselves, without being required to send in a work order and use the services of a carpenter, electrician, painter, or computer technician. If the department can show that the job is simple and that there is a person capable of handling it, then permission is granted to do it "in house."

6. When travel funds are low, senior faculty members who are making presentations at national meetings may double as recruiters, interviewing persons who may be interested in applying for positions in the department.

D. How can we get input for the continuous revitalization of curriculum and also meet the community's needs for our graduates as "state of the art" professionals?

1. Some large corporations have developed innovative programs in which the company encourages specialists-engineers, computer specialists, statisticians - to teach one or more classes during work time at the company expense. The company do-nates the time during work hours, and the employee donates time for preparation and grading. The equipment and processes used by the corporation let faculty and students know what is expected by potential employers of students, and the companies often loan equipment to the campuses.

2. To assist with classroom instruction, some businesses and organizations have donated software and funds to departments and faculty members. Their reasoning is that the software with which the students become familiar in their college days will be their preference after graduation.

3. In some schools, an all-day workshop is held for all members of department and school curriculum committees at both the graduate and undergraduate levels, with the department chairs, the dean, and associate dean. Also invited to this all-day session are persons from organizations in the community who are the potential employers of the students in the discipline, who act as advisors during the process of addressing curriculum issues during the morning. After lunch, the advisors from the community usually leave, and the session becomes an 
active work period to develop the changes needed to update the department course offerings in line with the long-term goals of the school and university.

4. Some schools have faculty intern programs in which faculty work in the community in a discipline-related field in the summer or during other breaks.

5. A school or department "match maker" can match community needs with faculty expertise and interest.

6. Some universities have an exchange program in which faculty and external advisors spend a day or two on each other's jobs. This facilitates the process of mutual understanding of community needs and the ability of the university to respond.

7. Advisory Boards can provide feedback on community needs and assist in projects such as workshop sessions for the community on specifically identified topics of interest.

8. When a national figure comes to the campus, a breakfast session with community leaders is a valued opportunity for interaction and strengthens the university-community alliance.

9. Many departments have an Advisory Board in addition to School and University Advisory Boards. Persons from the specialized field in the community can provide valuable insights into the future of the profession and current issues that may affect the field. They can also provide contacts for student and faculty internships and speakers for special occasions.

E. What are ways in which a University on a miniscule budget can facilitate faculty and staff development?

1. Many universities offer processes to enable faculty to retool themselves. Assigned time out of the classroom is sometimes available for projects to improve teaching areas. A fee waiver system is also available many places, in which faculty and staff may enroll in courses on the home campus or in cooperating institutions with the normal fees waived.

2. Cooperative projects across school lines can provide benefits for all involved. A cooperative project between a Human Resources Management department in the School of Business Administration and the Radio-TV department in the School of Fine Arts made possible the production of video vignettes to provide training in analysis of leadership styles and 
their consequences. These tapes were used in the classroom as a common experience preceding exercises and analysis papers, and also gave Fine Arts students experience in acting, directing, producing and editing video segments. These students had copies of the tape segment they worked on to back up experiences listed on their resumes and also got project credit as part of their course work.

3. Some institutions have established a University Academy to bring people together to foster interdisciplinary research and exchange.

4. Some universities have a day between semesters designated for inservice training by faculty for faculty. Some of these sessions deal with the "how tos" of research as well as other special topics.

5. Some colleges and universities have been successful in developing and using a no or low cost personalized Professional Development Plan. A personalized activity plan spells out goals for one year, five years, and a career plan.

6. When training funds are low, the few events that are scheduled can be videotaped, allowing replay for those who missed the event and a replaying several months later for reinforcement or orientation of new employees. One videotaped event on stress reduction included both concepts and exercises. Replaying of this tape is useful just before the start of each semester, when distressed students descend on department staff and on University "window workers." Other useful sessions to tape deal with pay procedures and any process where numerous errors have occurred.

7. Another money-saver is to approach faculty who are in need of university service experiences as they advance through the ranks and who have expertise that would be helpful for staff. Faculty from Management and Psychology have led "Window Workshops" for persons behind windows who get the brunt of student upsets from long lines and tangled schedules. Other faculty have led Time Management workshops, Stress Management workshops, noon-time exercise sessions, noon-time meditation sessions, and Conflict Management workshops.

8. Quality Circles have been very successful with specialized staff groups. One Purchasing Department moved the turnaround time of papers coming in from 23 days to 4 days by using this approach. Other groups have saved money by finding less 
expensive ways to meet their needs. Examples of such groups are extension staff, custodial staff, building and grounds staff, campus services, and environmental systems.

9. Faculty from any part of the campus who have received training as facilitators can work as in-house process consultants for departments, rather than bringing in outside consultants.

F. How can we encourage a mutually supportive universitycommunity relationship?

1. In one instance where there was a lack of adequate funding for student services, a program called "Adopt a Student" was created with the assistance of an advisory board. With community business persons acting as mentors, this program has been especially effective with minority students. Another project linked professional women with foreign women students.

2. Specialty advisory boards also take the place of outside consultants. These can be in management of information systems, accounting, theater arts, hotel management, engineering management, dietetics, social work, etc.

3. Organizations and individuals in the community are often pleased to contribute services or funds for special research projects or the presentation of papers. They also can provide help in designing or printing brochures, and contacts in the industry can sometimes provide airplane passes to assist faculty in presenting research papers at national meetings.

4. Some organizations are able to loan equipment needed for research projects for periods of six months or more.

5. Some institutions circulate a list of faculty members available to speak to community groups as a public service. The brochure often lists the topics in which the faculty are specialists.

Budget problems are common in almost every aspect of life today, whether it is the public or private sector. However, valued goals should not be abandoned arbitrarily. A multitude of options exist in which all participants win-those who give and those who receive. There is support available for those creative practitioners whose dreams exceed their bank accounts. 